Lightвown, J. W. (1954). J. gen. Microbiol. 11, 477-492.

\title{
An. Antagonist of Streptomycin and Dihydrostreptomycin produced by Pseudomonas aeruginosa
}

\author{
By J. W. LIGHTBOWN \\ National Institute for Medical Research, Mill Hill, London, N.w. 7
}

SUMMARY: A substance produced by Pseudomonas aeruginosa ( $P$. pyocyanea) which antagonizes the activity of streptomycin and dihydrostreptomycin, and which will itself inhibit bacterial growth in low concentrations, has been isolated in a crystalline form.

The antagonist at $0.01 \mu \mathrm{g} . / \mathrm{ml}$. was capable of antagonizing the action of 1000 times its weight of dihydrostreptomycin against Bacillus subtilis or B. pumilus. It was much less active against Escherichia coli. Growth of B. subtilis and B. pumilus was inhibited by less than $1 \mu \mathrm{g}$. antagonist/ml. under conditions which required a concentration of $6 \mu \mathrm{g}$. dihydrostreptomycin sulphate $/ \mathrm{ml}$. to inhibit growth.

A method of assay of antagonist activity, capable of assaying solutions containing $0.01 \mu \mathrm{g}$. antagonist $/ \mathrm{ml}$., was developed. It was a cup-plate method which depended on the production of zones of exhibition. Plates poured with seeded nutrient agar containing an inhibitory concentration of dihydrostreptomycin were used, and the samples of antagonist were placed on the surface of the agar in fish spine beads. The zones of exhibition developed during incubation of the plates and the potency of the samples could be determined from a comparison with zones produced by a standard preparation on the same plate.

The antagonist was produced by most strains of Pseudomonas aeruginosa under favourable conditions. Its production in fluid culture depended on vigorous aeration, but too high an aeration rate or foaming of the culture produced low yields. Strains of other organisms which were examined, for example, Staphylococcus aureus, Escherichia coli, Serratia marcescens, Bacterium bodenheimer, streptococci of Lancefield's Group D, Bacillus subtilis and B. pumilus, did not produce antagonist.

The antagonist was extracted from fluid culture by $n$-butanol; the butanol was removed by distillation in an atmosphere of nitrogen, and the residue fractionated by precipitation from benzene solution by addition of light petroleum. The success of the fractionation was dependent on obtaining an initial butanol extract containing at least $100 \mu \mathrm{g}$. antagonist/mg. total solids. This in turn was dependent on the use of a simple chemically defined culture medium for production, and the choice of a strain of Pseudomonas aeruginosa which produced a high yield of antagonist. The crystalline antagonist has the formula $\mathrm{C}_{17-18} \mathrm{H}_{23-24} \mathrm{NO}_{2}$ and a molecular weight of the order $300-400$. It is stable in the dry crystalline state, but readily oxidized in solution. It is soluble in ethanol and butanol, less soluble in benzene, and relatively insoluble in light petroleum. Its maximum solubility in water at room temperature at $\mathrm{pH} \mathbf{7 \cdot 0}$ is $c .10 \mu \mathrm{g} . / \mathrm{ml}$; at $\mathrm{pH} 9.0$ it is $20-30 \mu \mathrm{g} . / \mathrm{ml}$.

The work described in this paper developed from a search for an effective means of inactivating streptomycin and dihydrostreptomycin which could be applied in sterility tests of these antibiotics. Streptomycin may be inactivated by carbonyl reagents, and sterility tests based on this principle are used. As these reagents are in themselves bacteriostatic, the tests have not proved very satisfactory. Dihydrostreptomycin differs from streptomycin in having the labile aldehyde group reduced, so that its activity is unaffected by carbonyl reagents. It is a very stable molecule and can only be destroyed by chemical means 
which also destroy contaminating bacteria. Since substances which inactivate dihydrostreptomycin are almost certain to inactivate streptomycin whilst the reverse does not necessarily obtain, dihydrostreptomycin has been used in most of this investigation.

Fitzgerald \& Bernheim (1948) described abolition of streptomycin activity against Escherichia coli and Mycobacterium tuberculosis by urea, uric acid, uracil, parabanic acid and various purine compounds. These substances were tested against dihydrostreptomycin, using Bacillus subtilis and Staphylococcus aureus as test organisms, and found to be inactive.

Rhymer, Wallace, Byers \& Carter (1947) reported that soya-bean lipositol antagonized streptomycin, but I have been unable to confirm this with preparations made by these workers.

Sureau, Arquie, Boyer \& Saviard (1948) described a 'streptomycinase' which was produced by Pseudomonas aeruginosa and by streptococci of Group D; Simkovics \& Karossy (1948) also reported a 'streptomycinase' produced by $\boldsymbol{P}$. aeruginosa and by Escherichia coli, Salmonella typhi and $S$. paratyphi. Linz (1948) described the antagonism of streptomycin by heattreated suspensions of Pseudomonas aeruginosa.

Lightbown (1950) reported that culture filtrates of Pseudomonas aeruginosa antagonized dihydrostreptomycin as well as streptomycin, and showed that the active factor was not an enzyme as implied by the term 'streptomycinase'. The active factor was shown to withstand boiling $0 \cdot 1 \mathrm{~N}-\mathrm{HCl}$ or $\mathrm{NaOH}$, to diffuse through cellophan and to be extractable by lipid solvents. These properties were later confirmed by von Grumbach (1951). This paper describes the preparation and isolation of the antagonist in a crystalline form. It is probable that this antagonist is responsible for the 'streptomycin inhibition' activity of preparations of $\boldsymbol{P}$. aeruginosa described by Bergman, Grubb, Bergström \& Rösch (1954) at the time this paper was submitted for publication. It is interesting to note that these workers report that their preparations also antagonize the activity of neomycin.

\section{Assay of antagonist}

Standard preparation. Early in this work it was apparent that the activity of preparations of antagonist was markedly affected by such factors as pH value, temperature of incubation, nature of culture medium used in assay, and choice of test organism. In order to correlate measurements of activity obtained on different samples at different times, it was necessary to have a standard of antagonist activity. In the early experiments, a culture filtrate of Pseudomonas aeruginosa was set aside and to it was assigned an arbitrary potency of $1 \mathrm{u} . / \mathrm{ml}$. This unit of activity was used throughout the experiments; before the first standard sample was exhausted it was replaced by a second standard, which was assayed against the first. During 3 years the standard of activity has been passed through twenty consecutive standard preparations. The later ones have been prepared from the purest samples of antagonist available at the time, and the unit has been the activity contained in approximately $0.008 \mathrm{mg}$. of recrystallized material. 
In the early experiments, samples were assayed by adding them to known solutions of dihydrostreptomycin in phosphate buffer, and measuring the residual antibiotic activity, by a modified cup-plate technique using fish spine beads (Humphrey \& Lightbown, 1952). By this method a one-plate assay with sixty-four cups would just indicate a difference in activity of $30 \%$ between two antagonist preparations containing approximately $1 \mathrm{u} . / \mathrm{ml}$. The activity of a preparation containing less than $0 \cdot 3 \mathrm{u} . / \mathrm{ml}$. could not be measured.

An alternative and much more sensitive assay was developed in which cups containing the preparations of antagonist to be assayed were placed on plates of deep-seeded nutrient agar containing a concentration of dihydrostreptomycin sufficient to prevent growth of the test organism in the absence of antagonist. After incubation, sharply defined zones of growth appeared around the cups, and the potency of the samples assayed could be calculated from the diameters of the zones as in a normal antibiotic cup-plate assay.
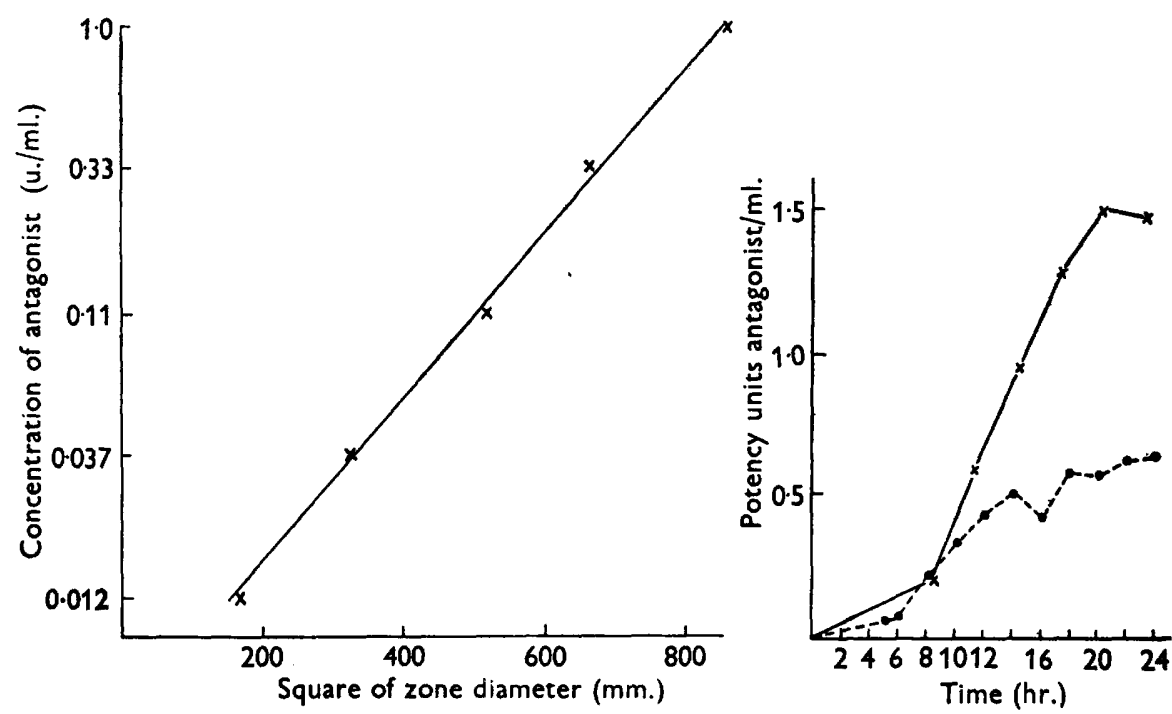

Fig. 1. Dose response curve for assay of antagonist by production of exhibition zones in nutrient agar containing dihydrostreptomycin and seeded with Bacillus pumilus.

Fig. 2. Effect of foaming on production of antagonist in stirred culture of Pseudomonas aeruginosa. Aeration constant (Wise, 1951) $1 \cdot 45^{-1}, \times-\times$, foaming controlled by $1.2 \mathrm{~g}$. of silicone antifoam/1. of culture; - - , foaming not controlled by $0.6 \mathrm{~g}$. of silicone antifoam/1. of culture. Each curve represents the mean of values obtained from 6 replicate cultures.

Fig. 1 shows a typical dose response curve in which the square of the exhibition zone diameter is proportional to the log. of the concentration of antagonist. Since it was shown by Humphrey \& Lightbown (1952) that the difference between linear and square relationship in cup-plate diffusion assays only becomes significant with very accurate assays, or when the dose levels are widely spaced, a linear relationship has been used in most of the assays. With a $6 \times 6$ Latin square design, i.e. 36 cups/plate, it is possible to detect a difference 
of potency of $6-10 \%$ between two different preparations. For a given concentration of antagonist, the zone diameter is inversely proportional to the concentration of dihydrostreptomycin in the agar, but as the zone diameter increases the edge of the zone becomes less sharp. With the assay system normally used, giving reasonably sharp edges, it is possible to estimate activities down to $0.01 \mathrm{u}$. antagonist $/ \mathrm{ml}$.

The medium used in the assays was Wright infusion agar (Mackie \& McCartney, 1946) containing $1 \%$ of sodium dihydrogen phosphate and adjusted to a final $\mathrm{pH}$ value of $\mathbf{7 \cdot 2}$. The test organism used was either Bacillus subtilis I.C.I. strain (NCTC 8236) or B. pumilus Mill Hill strain (NCTC 8241), seeded at a density of approximately $6 \times 10^{7}$ viable spores $/ \mathrm{ml}$. medium. Immediately before pouring the seeded agar, at a temperature of not more than $80^{\circ}$, dihydrostreptomycin sulphate solution was added to give a final concentration of from 8 to $24 \mu \mathrm{g}$. $/ \mathrm{ml}$. The optimum concentration for each batch of medium had to be determined experimentally. Fish spine beads containing the assay samples were placed on the agar, after drying the plates at room temperature for $30 \mathrm{~min}$., and the plates immediately incubated at $37^{\circ}$ overnight. The temperature of incubation had to be carefully controlled, as a variation of $\pm 2^{\circ}$ gave plates with either no growth at all or confluent zones. Much sharper zone edges were obtained when the assay plates were allowed to stand overnight at room temperature for diffusion of antagonist and subsequently incubated at $37^{\circ}$. Pl. 1, fig. 1, shows an assay plate which was obtained in this way. Zone diameters were measured on a screen after $\times 10$ magnification.

Where possible, samples for assay were dissolved in phosphate buffer of pH 9.0 and $\mu=0 \cdot 1$. Below $\mathrm{pH} 8 \cdot 0$, the solubility of the antagonist is approxi-

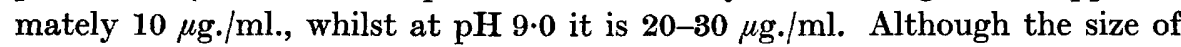
the zone diameter is affected by the $\mathrm{pH}$ value of the medium, it was found that the $\mathrm{pH}$ value of the test solution was not critical when the medium was buffered.

Samples dissolved in organic solvents were sometimes assayed by depositing a known small volume, e.g. $1 \mu \mathrm{l}$., on filter-paper and placing the filter-paper on the surface of the assay plate. The value of this method was limited by the low solubility of the antagonist and by the presence of inert lipid material which affected the transfer of the antagonist from paper to agar. Both these factors tended to cause an underestimation of activity, but in spite of this the method proved very useful.

\section{Production of antagonist}

Choice of strain. Thirty strains of Pseudomonas aeruginosa were compared, by a technique already described (Lightbown, 1950), for their power of producing antagonist. The strains were grown on the surface of cellophan sheet laid on nutrient agar containing dihydrostreptomycin and seeded with Bacillus subtilis. Large assay plates were used, which accommodated nine strains per plate. It was found more satisfactory to grow the strains within rings of soft paraffin deposited on the cellophan by means of a hot cork borer. In this way 
the area of growth of Pseudomonas aeruginosa was maintained constant and the zones of exhibition could be compared.

Twenty-three of the strains tested produced antagonist. Amongst these were strains which produced blue, yellow, green and red cultures. Some strains produced relatively large amounts of antibiotic material, which was made evident by a clear zone of inhibition inside the zone of exhibition. The strain finally chosen was a variant derived from the L III strain described by Don \& van den Ende (1950). This organism produced a high yield of antagonist and relatively little antibiotic. It was maintained by daily subculture on nutrient agar slopes and dried by the method of Stamp (1947). The strain was very variable, and unless subcultured daily it was liable to lose completely or partially its power of production of antagonist. Examination of individual colonies showed wide variation in antagonist production from colony to colony; some colonies produced none at all. There was no evident correlation between cultural characteristics and antagonist production. Colonies which produced no antagonist sometimes gave rise to a small number of active colonies on repeated plating.

Culture medium. Good yields of antagonist were obtained on most of the complex culture media tested, for example, Wright infusion broth, Hartley digest broth, $1 \%$ peptone water and C.C.Y. (Mackie \& McCartney, 1946). The addition of a fermentable carbohydrate, which resulted in a culture with an acid $\mathrm{pH}$ value, decreased the yield; the highest yields of antagonist were found in cultures of $\mathrm{pH} \mathrm{8-9}$ after overnight growth.

The chemically defined media described by Turfitt (1936) gave poor yields of antagonist. With ammonium acetate as the sole source of carbon and nitrogen, together with $\mathrm{K}_{2} \mathrm{HPO}_{4}$ and $\mathrm{MgSO}_{4}$, quite good yields of antagonist were obtained, but the strain was very unstable, losing the power to produce antagonist when subcultured daily. The medium finally chosen was: ammonium lactate, $0.5 \% ; \mathrm{K}_{2} \mathrm{HPO}_{4}, 0 \cdot 1 \% ; \mathrm{MgSO}_{4} .7 \mathrm{H}_{2} \mathrm{O}, 0.05 \%$; distilled water, adjusted to $\mathrm{pH} \mathrm{7 \cdot 5}$. The original L III strain grew well in this medium after two or three subcultures. By repeatedly plating on ammonium lactate medium, solidified with $1.0 \%$ washed New Zealand agar, and testing isolated colonies by the cellophan technique and by assay of culture filtrates, a comparatively stable strain was obtained which gave higher yields in the ammonium lactate medium than in the more complex media. This strain was maintained in the dried state and could be revived at will with its properties unchanged.

Temperature of incubation was not critical between $30^{\circ}$ and $37 \cdot 5^{\circ}$, and a temperature of $35^{\circ}$ was usually used.

The degree of aeration was found to be very important. Static liquid cultures gave very low yields or no activity, and the culture usually became very viscid. Aeration by shaking in conical flasks at 100 cycles/min., using the machine described by Kantorowicz (1951), gave consistently high yields. With this machine it is possible to vary the degree of aeration by using shelves at different levels, so altering the throw of the flask, or by altering the ratio of volume of culture to volume of flask. Highest yields $(1-1.5 \mathrm{u} . / \mathrm{ml}$.) were obtained with the maximum throw of 4 in.; decrease of the throw to 2 in. 
decreased the yield by $50 \%$. The optimum ratio of culture volume to flask volume was $1: 8$; an increase in this ratio to $1: 5.7$ decreased the yield by $40 \%$. Decrease of this ratio below $1: 10$ also decreased the yield, but it was not clear whether this was an aeration effect, since below this ratio evaporation losses with consequent concentration of the medium become troublesome.

When attempts were made to grow large single batches of culture, using other methods of aeration, very low yields were obtained. Growth in the apparatus described by Mitchell (1949) gave no antagonist at all. Growth in 20 and 10 l. aspirators aerated by Doulton filter candles (A.P.D. 7-10 $\mu$ ) inserted through the tubulure gave irregular results. Yields of $0 \cdot 4, \mathrm{u}$. antagonist $/ \mathrm{ml}$. were obtained, but the method was abandoned, mainly because of the difficulty of controlling foaming at high aeration rates, e.g. 2 vol. air $/ \mathrm{vol}$. medium/min. Lesser degrees of aeration gave consistently low yields.

The culture apparatus described by Fraser (1951) gave yields up to $0.7 \mathrm{u}$. antagonist $/ \mathrm{ml}$. with an aeration rate of $40 \mathrm{vol}$. air/vol. medium $/ \mathrm{min}$., but evaporation of the culture was a serious problem and the volume that could be handled was small.

With the aid of the Medical Research Council's Antibiotics Research Station at Clevedon, good yields were obtained with batches of $300 \mathrm{l}$. ammonium lactate medium. Preliminary experiments carried out in the $5 \mathrm{l}$. stirred culture vessels described by Kelly, Miller \& Hale (1952) showed that there was an optimum aeration rate corresponding to an aeration constant (Wise, 1951) of $1.45 \mathrm{~min}^{-1}$. Under these conditions, potencies of 1-2 u. antagonist $/ \mathrm{ml}$. were regularly obtained. In cultures with aeration constants of 1.0 and 1.70 , the potencies were lower (Table 1 ).

Table 1. The maximum potency of antagonist (u./ml.) obtained in stirred flask cultures at different aeration constants (Wise, 1951) in the presence and absence of silicone antifoam.

Each value represents the mean of several experiments, the number of experiments being shown in brackets.

\begin{tabular}{|c|c|c|c|c|c|c|}
\hline \multicolumn{7}{|c|}{ Aeration constant } \\
\hline $2 \cdot 6$ & $1 \cdot 7$ & 1.45 & 1.0 & $0 \cdot 84$ & 0.7 & 0.25 \\
\hline \multicolumn{7}{|c|}{ Potency (u./ml.) and number of experiments ( ) } \\
\hline 0.33 & 0.52 & $1 \cdot 15$ & 0.50 & $0 \cdot 63$ & 0.27 & 0.0 \\
\hline
\end{tabular}

$\begin{array}{lccccccc}\text { Antifoam present } & 0.33 & 0.52 & 1.15 & 0.50 & 0.63 & 0.27 & 0.044 \\ & (2) & (4) & (10) & (4) & (6) & (2) & (2) \\ \text { Antifoam absent } & 0.21 & - & - & - & 0.11 & 0.31 & 0.039\end{array}$

(2) - $\quad$ (2) $\quad$ (2)

Foaming was controlled by using high concentrations (e.g. $1.2 \mathrm{~g} . / 1$.) of D.C. Antifoam A (Dow Corning product); smaller concentrations were ineffective. The need to control foaming was not only the practical one of protecting the outlet filters, for it was found that low titres were always obtained in the presence of foam (Fig. 2). The effect on yield of antagonist of excess aeration and of foaming are partially explained by the fact that the antagonist is easily oxidized. Triamyl citrate also controlled foaming, but its use was abandoned because it increased the difficulty of extracting the active factor. 
Length of incubation. The production of antagonist followed the growth curve of the organism; production ceased when the stationary growth phase was reached. At the higher aeration rates, continued aeration during the stationary phase of growth caused a decrease in potency.

The conditions for a typical 300 l. culture are given in the Appendix to this paper.

Methods of extraction and purification. Extraction by diethyl ether of culture acidified with $\mathrm{HCl}$ to $\mathrm{pH} \mathrm{5.0} \mathrm{removed} \mathrm{the} \mathrm{antagonist} \mathrm{but} \mathrm{loss} \mathrm{of} \mathrm{activity} \mathrm{was}$ liable to occur during subsequent concentration by evaporation of the ether. The active factor was adsorbed from whole culture by charcoal, activated alumina (British Drug Houses Ltd.), calcium carbonate, kaolin and fullers earth, and could be eluted from all except carbon by $95 \%$ ethanol.

The most satisfactory procedure proved to be extraction by $n$-butanol of

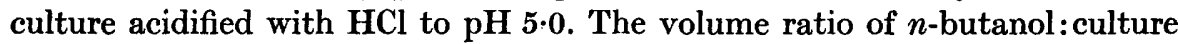
was decreased to a minimum, i.e. 1:20 in order to decrease the amount of inert material extracted. With this ratio over $95 \%$ of the activity could be removed by a single extraction. The butanol extract was concentrated by distillation in an atmosphere of oxygen-free nitrogen. In the presence of even a small amount of air, up to $50 \%$ of the activity could be lost in the final stages of distillation when the residue became very concentrated, although in the earlier stages no loss occurred. The residue was a dark brown viscous oil.

Attempts to fractionate the brown oil by methods used in previous examinations of the products of Pseudomonas aeruginosa by Hays et al. (1945), and by Bergström, Theorell \& Davide (1946) gave no useful results. Chromatographic separation on alumina columns and on paper, with water saturated butanol, as well as reverse phase chromatography using benzene and borate

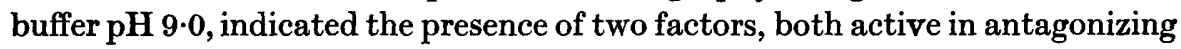
streptomycin and both active inhibitors of bacterial growth. No separation of antagonist from associated antibiotic activity was obtained. On paper strips the activity frequently disappeared altogether, probably owing to oxidation. With the reverse phase benzene and borate buffer column, which was the most promising system, the quantities that could be handled were limited by the low solubility of the antagonist.

Fractionation depending on varying solubility of different constituents of the crude extract in organic solvents was successful. All the antagonist of the crude oil could be extracted by a small volume of hot benzene, and subsequent addition of light petroleum $\left(80-100^{\circ}\right)$ precipitated a large proportion of inert material, including most of the pigment, at a solvent ratio of 1 part of benzene to 2 parts of light petroleum. On standing, some of the antagonist also precipitated, but it was possible to remove the inert material first by centrifuging. This stage of the fractionation had to be carried out rapidly as with some preparations the active material began to precipitate after several minutes. The addition of a further 2 vol. of light petroleum to the supernatant precipitated most of the remaining antagonist. By repeating the procedure of precipitation from benzene with light petroleum several times, the antagonist with a potency of 100-120 u./mg. was obtained in a crystalline form (Pl. 1, figs. 2a, b). 
The success of this method depended upon the proportion of antagonist to inert material in the crude butanol extract, and on the nature of the impurities. Table 2 indicates the variation in activity of the crude extracts obtained, by the use of different methods of cultivation and extraction. Although cultivation in a complex medium gave high potencies, the crude extract as might be expected contained a smaller percentage of activity. When the concentration of antagonist in the crude extract was less than $10 \mathrm{u} . / \mathrm{mg}$., the benzene and light petroleum fractionation was unsuccessful. For this reason, it was essential to use a culture medium of simple composition, and to extract as little inert material as possible in the initial extraction by using a minimum volume of solvent.

The crystalline material obtained as deseribed was recrystallized from hot benzene, and from hot $50 \%$ aqueous ethanol to a constant activity of approximately $125 \mathrm{u} . / \mathrm{mg}$. It was pale cream in colour, crystallizing as very thin rectangular plates from benzene, and imperfectly as sheaves of lanceolate plates from ethanol. Attempts to obtain large perfect crystals by slow crystallization were unsuccessful, usually resulting in oxidation with darkening and loss of activity. The melting point was $147^{\circ}$. Examination in a density column by the method of Low \& Richards (1952) showed the material to be homogeneous with a density of 1.172. Analysis showed the presence of only the elements $\mathrm{C}, \mathrm{H}, \mathrm{N}$ and $\mathrm{O}$, and gave values of $\mathrm{C} 75 \cdot 0, \mathrm{H} 8 \cdot 4, \mathrm{~N} 5 \cdot 0$, corresponding to an empirical formula $\left(\mathrm{C}_{17-18} \mathrm{H}_{23-24} \mathrm{NO}_{2}\right)$. The material was stable in the dry crystalline state but was readily oxidized in solution. Its diffusion constant in $2 \%$ agar was $0.0178 \mathrm{~cm} .2 / \mathrm{hr}$., which would suggest a molecular weight of the order of $300-400$.

An examination of the ultraviolet absorption spectrum showed the material to be different from the pyocyanea compounds of Hays et al. (1945) although suggesting some similarity. An investigation of the chemistry of the crystalline material has been carried out by J. W. Cornforth and A. T. James (1954) who have reported that the material isolated is a mixture of several closely related components. One component has been tentatively identified as 2-heptyl4-hydroxy-quinoline- $N$-oxide; synthetic material of this formula has approximately $30 \%$ of the activity of the natural material isolated above; the second component is thought to be 2 -(2'-nonenyl)-4-hydroxy-quinoline- $N$-oxide.

\section{Biological properties}

Although the mode of action of the antagonist has not yet been fully elucidated, the following biological properties are of interest.

Activity against streptomycin and dihydrostreptomycin. The activity of the antagonist against these two antibiotics is markedly affected by the $\mathrm{pH}$ value of the test system; the activity increases with decrease in $\mathrm{pH}$ value. Since activity of streptomycin decreases with decrease in $\mathrm{pH}$ value, this effect on antagonist activity might be expected. However, the increase in antagonist activity for a given decrease in $\mathrm{pH}$ value is greater than would be expected from the change in streptomycin activity.

The ratio of antagonist to antibiotic necessary to inhibit the activity of the 


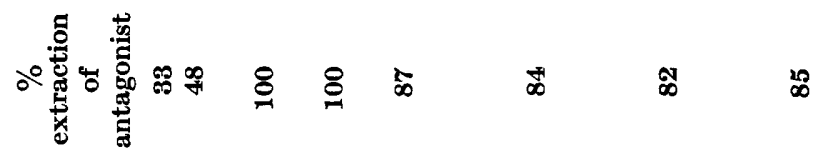

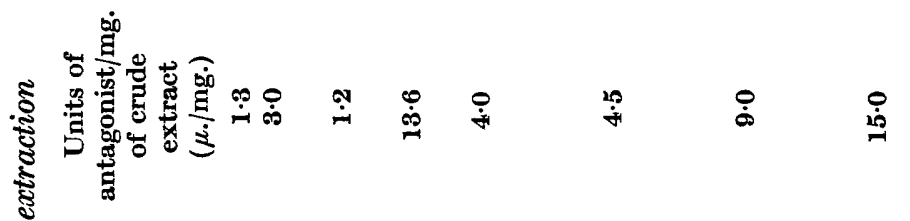

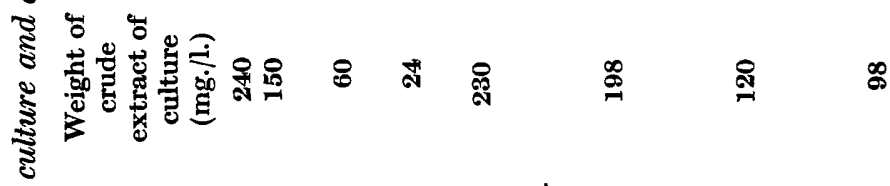

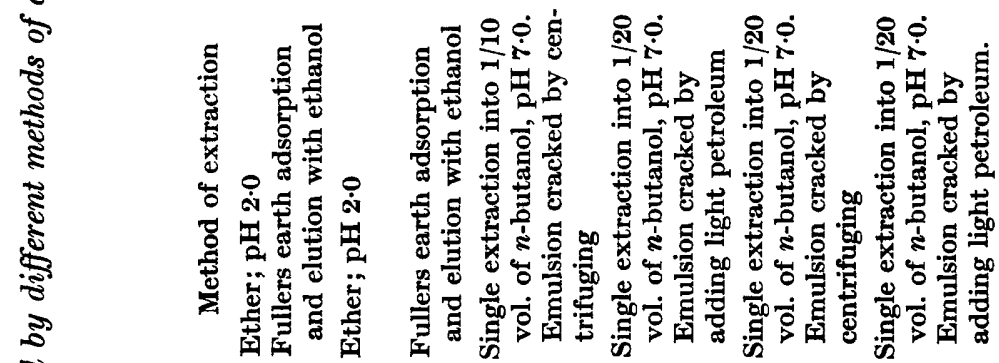

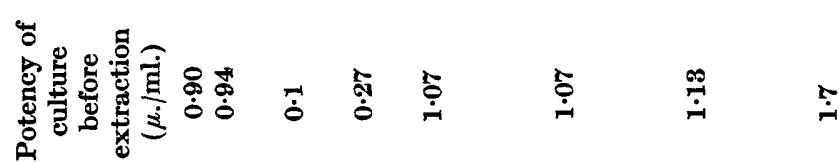

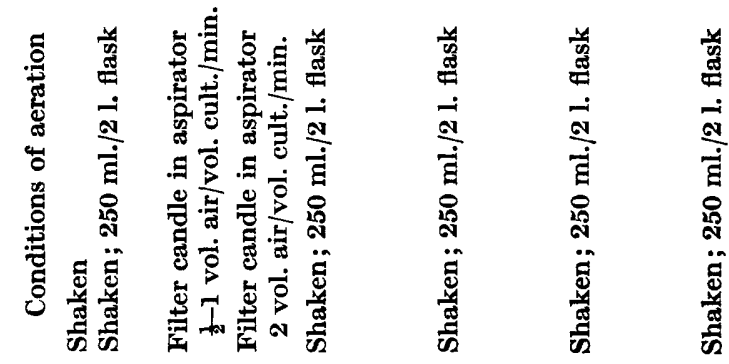

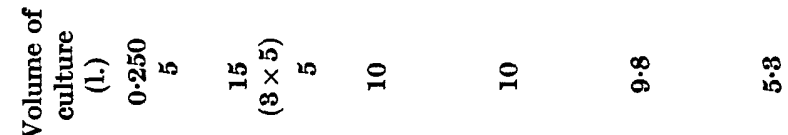

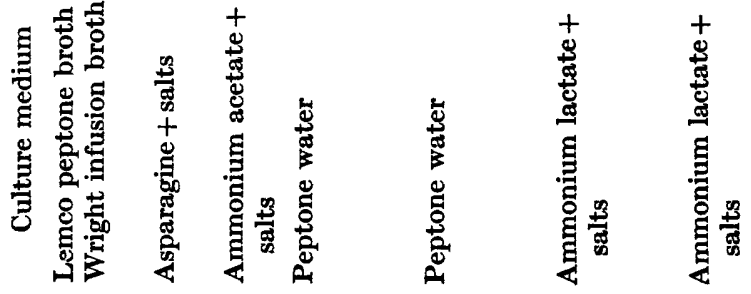


dihydrostreptomycin has been determined in two ways. The concentration of antagonist at the periphery of a zone of stimulation, at the time at which the zone is fixed, may be calculated by the formula of Humphrey \& Lightbown (1952) from data obtained in diffusion experiments. The concentrations so calculated for Bacillus pumilus in Wright infusion agar, buffered at $\mathrm{pH} 7 \cdot 2$, are of the order of $0.01-0.02 \mu \mathrm{g} . / \mathrm{ml}$. In these experiments the concentration of dihydrostreptomycin sulphate in the plates was $16 \mu \mathrm{g} . / \mathrm{ml}$. In the absence of antagonist, however, growth of the test organism only occurred at concentrations of less than $6 \mu \mathrm{g}$. dihydrostreptomycin sulphate per ml. Thus, under these circumstances, the antagonist is antagonizing 500 to 1000 times its weight of dihydrostreptomycin sulphate.

In the liquid chemically defined medium described by Roberts (1934) and with Bacillus pumilus as test organism, the antagonist antagonized 60-80 times its weight of dihydrostreptomycin sulphate at $\mathbf{p H ~ 7 \cdot 2 . ~ I n ~ e x p e r i m e n t s ~}$ of this type the end-point is fixed by a relatively small number of more resistant cells, which might explain the lower ratio.

Antibiotic activity of antagonist. Crude preparations of antagonist always inhibited growth when used in high concentrations, and it was at first thought that this antibiotic activity was probably due to contaminating antibiotic substances. Although this growth inhibitory effect decreased with purification, the crystalline preparation of antagonist could still inhibit growth. In liquid chemically defined medium of $\mathrm{pH} 7 \cdot 2$, seeded with Bacillus subtilis, the minimum inhibitory concentration of antagonist was about $5 \mu \mathrm{g} . / \mathrm{ml}$. compared with c. $50 \mu \mathrm{g}$. dihydrostreptomycin sulphate/ml. In buffered Wright infusion agar at $\mathrm{pH} 7 \cdot 2$, also with $B$. subtilis as test organism, the equivalent values were $0.6 \mu \mathrm{g}$. antagonist $/ \mathrm{ml}$. and $6 \mu \mathrm{g}$. dihydrostreptomycin sulphate/ml. The antibiotic activity of antagonist increased with decrease in $\mathrm{pH}$ value of the test system.

Effect on antagonist activity of previous exposure of test organism to dihydrostreptomycin. When a plate of seeded nutrient agar containing an inhibitory concentration of dihydrostreptomycin was incubated at $37^{\circ}$, and cups of antagonist were added at intervals of time after beginning incubation, no zones of exhibition were obtained around cups added after $4 \mathrm{hr}$. incubation (Fig. 3). It appears that the antagonist can only protect cells against the activity of dihydrostreptomycin and cannot reverse its bactericidal effect.

Shape and nature of zones of inhibition and exhibition. It is interesting to compare the shape and nature of the zones of inhibition and exhibition obtained in assays of dihydrostreptomycin and antagonist (Fig. 4, $a$ and $b$, shows diagrammatically a vertical section of each type of zone). Dihydrostreptomycin is less active in the depths of the agar, resulting in a cup-shape zone of inhibition; with the antagonist, the zone is dome-shaped. In the inhibition zone, growth only occurs as a thin layer on the surface of the agar and then down the edge of the zone; in the exhibition zone, on the other hand, growth occurs uniformly throughout the depths of the agar. This ability to support growth deep in the agar is also seen when a solution of antagonist is placed on the surface of seeded agar which contains no dihydrostreptomycin. When 
a section of the agar is examined after incubation, it can be seen that in absence of antagonist the growth is in the surface layer, whilst in presence of antagonist growth occurs much more deeply (Fig. 4c).

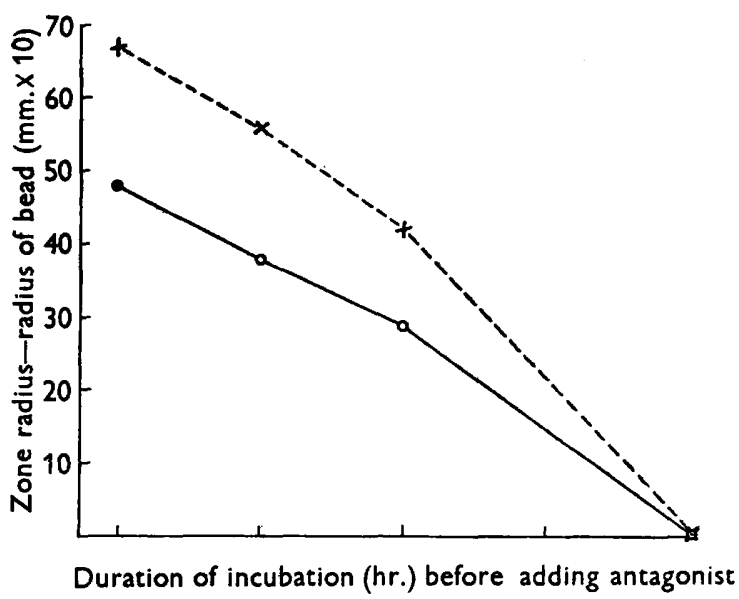

Fig. 3. Variation in size of exhibition zones produced by antagonist at 1 and $0 \cdot 3 \mathrm{u} . / \mathrm{ml}$. added at intervals after beginning incubation of the assay plate at $37^{\circ}$. Test organism : Bacillus pumilus. Medium: buffered Wright infusion agar containing $16 \mu \mathrm{g}$. dihydrostreptomycin $/ \mathrm{ml}$. Each point represents the mean of 9 diameters; $\times \cdots \times, 1$ u. antagonist $/ \mathrm{ml}$.; $\mathrm{O}-\mathrm{O}, 0.3 \mathrm{u}$. antagonist $/ \mathrm{ml}$.

\section{(a)}

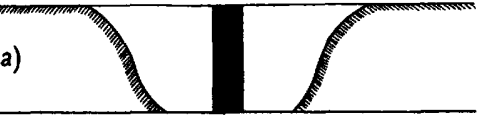

(b)

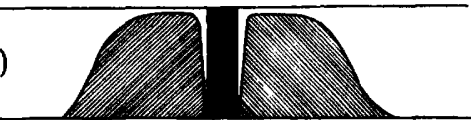

(c)

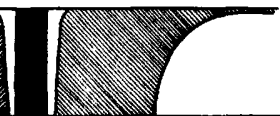

Fig. 4. Diagrammatical representation of the vertical section of zones obtained in punch hole plates, deep seeded with Bacillus subtilis. (a) With dihydrostreptomycin diffusing from the punch hole; $(b)$ with antagonist diffusing into seeded agar containing dihydrostreptomycin; $(c)$ with antagonist diffusing into seeded agar containing no dihydrostreptomycin. The shaded areas represent the distribution of growth in the agar and show how activity of dihydrostreptomycin and antagonist vary at different depths in the agar.

\section{DISCUSSION}

Apart from nucleic acid and some other complex anions, such as heparin, which are capable of precipitating dihydrostreptomycin and streptomycin from solution, the material described here is the only one known that will antagonize 
dihydrostreptomycin. Many substances which have been reported to have an effect against streptomycin have been tested by the methods used in this paper and have been found without activity against dihydrostreptomycin. Besides the compounds mentioned earlier, yeast extract, yeast nucleic acid, inositol, various components of the citric acid cycle, mercaptoacetic acid, cysteine, pyocyanin, $\alpha$-oxyphenazine, a series of dicarboxylic acids (which it was thought might react with the two guanido groups of streptidine) and various substituted quinoline derivatives have been tested without success. The antagonist has no activity against penicillin or aureomycin.

The production of antagonist has been found only amongst $P$ seudomonas species. A number of other organisms has been examined, i.e. strains of Staphylococcus aureus, Escherichia coli, Serratia marcescens, Bacterium bodenheimer, Bacillus subtilis and B. pumilus, and several strains of streptococci of Lancefield's group D. With regard to group D streptococci, activity was reported from this organism by Sureau et al. (1948), but Rybak, Grumbach \& Gros (1949) were unable to confirm this observation even with the original strain used by Sureau et al. (1948). Bearing in mind the ease of oxidation of the antagonist and the vigorous aeration necessary for its production by Pseudomonas aeruginosa, it may well be that the simultaneous production of reducing substances, e.g. pyocyanin, is necessary to allow accumulation of antagonist in the culture. It was noticed with $\boldsymbol{P}$. aeruginosa that conditions of cultivation which produced a high yield of antagonist usually resulted in good pigment formation. The addition of dihydrostreptomycin to growing cultures of $\boldsymbol{P}$. aeruginosa did not result in an increased yield of antagonist, nor did previous exposure of the $\boldsymbol{P}$. aeruginosa to dihydrostreptomycin with resulting increase in resistance of the organism to this antibiotic.

The antagonism of dihydrostreptomycin activity has been studied only with Bacillus subtilis, B. pumilus, strains of Staphylococcus aureus and of Escherichia coli. With the first three organisms the antagonism is quite clear cut, but with $E$. coli the results obtained were equivocal. Of eleven different strains examined, ten (which were sensitive to dihydrostreptomycin) showed a very slight response to the antagonist in the presence of dihydrostreptomycin when tested in agar. The mechanism of the antagonism appears to be a biological one, and it is hoped that a further study of the properties of the antagonist may help to elucidate the mode of action of streptomycin. It seems unlikely that the antagonist will be of value in testing the sterility of samples of streptomycin and dihydrostreptomycin because of its low solubility and bacteriostatic activity in high concentrations, and because of its low activity against $\boldsymbol{E}$. coli.

I wish to express my thanks to Dr J. H. Humphrey for his helpful encouragement and criticism during the course of this work; and to Messrs B. K. Kelly, G. A. Miller, C. W. Hale and Miss N. Smith of the Medical Research Council's Antibiotics Research Station, Clevedon, for their advice and assistance in carrying out the large-scale cultivation and extraction. 


\section{REFERENCES}

Bergman, S., Grubb, R., Bergström, S. \& Rösch, H. (1954). Studies on an inhibitor of streptomycin and neomycin of bacterial origin. Antibiotics \& Chemother. 4, 493.

Bergström, S., Theoreli, H. \& Davide, H. (1946). Metabolic product of Pseudomonas pyocyanea, pyolipic acid, active against Mycobacterium tuberculosis. Ark. Kemi Min. Geol. A, 23, no. 13.

Connforth, J. W. \& James A. T. (1954). Some chemical properties of a naturally occurring antagonist of dihydrostreptomycin. Biochem $J$. (in the Press).

Don, P. A. \& Ende, M. van Den (1950). A study of the bacteriophages of Pseudomonas aeruginosa. J. Hyg., Camb. 48, 196.

Fitzgerald, R. J. \& Bernheim, F. (1948). The reversal of bacteriostatic action of streptomycin by urea. J. biol. Chem. 172, 845 .

Fraser, D. (1951). Apparatus for growth of aerobic bacteria and preparation of bacteriophage. J. Bact. 61, 115.

Grumbach, A. von (1951). Pseudomonas pyocyanea. Filtrat als Inaktivator von Streptomycin und Aktivator von Penicillin. Schweiz. Z. allg. Path. 14, 334.

Hays, E. E., Wells, C. I., Katzman, P. A., Cain, C. K., Jacobs, F. A., Thayer, S. A., Doisy, E. A., Gaby, W. L., Roberts, E. C., Muir, R. D., Carroll, C. J., Jones, L. R. \& WADE, N. J. (1945). Antibiotic substances produced by Pseudomonas aeruginosa. J. biol. Chem. 159, 725.

Heyningen, W. E. van (1949). A rapid concentrating still. Brit. J. exp. Path. 30, 302.

Humphrey, J. H. \& Lightbown, J. W. (1952). A general theory for plate assay of antibiotics with some practical applications. J. gen. Microbiol. 7, 129.

KANTOROWICz, $\mathbf{O}$. (1951). Shaking apparatus for the aeration of bacterial cultures. J. gen. Microbiol. 5, 276.

Keliy, B. K., Miller, G. A. \& Hale, C. W. (1952). Culture media for large scale production of micrococcin. J. gen. Microbiol. 6, 41.

Lightbown, J. W. (1950). An antagonist of dihydrostreptomycin and streptomycin produced by Pseudomonas pyocyanea. Nature, Lond. 166, 356.

Linz, R. (1948). Effet antagoniste des suspensions de bactéries chauffées sur la streptomycine; cas des bactéries résistantes. C.R. Soc. Biol., Paris, 142, 1438.

Low, B. W. \& Richards, F. M. (1952). The use of the gradient tube for the determination of crystal densities. J. Amer. chem. Soc. 74, 1660.

Mackie, T. J. \& MCCartney, J. E. (1946). Handbook of Practical Bacteriology, 7th ed. Edinburgh: E. and S. Livingstone Ltd.

Mrtchell, P. (1949). A new technique for stirred aerated culture. Nature, Lond. 164, 826.

Rhymer, I., Wallace, G. I., Byers, L. W. \& Carter, H. E. (1947). The antistreptomycin activity of lipositol. J. biol. Chem. 169, 457 .

Roberts, J. L. (1934). Endospore formation by Bacillus subtilis in a synthetic medium. Science, $79,432$.

Rybak, B., Grumbach, F. \& Gros, F. (1949). Étude sur quelques inhibitions de l'action de la streptomycine. Ann. Inst. Pasteur, 77, 237.

Simkovics, G. \& Karossy, S. (1948). Substances produced by micro-organisms inhibiting the action of antibiotics. Orv. Hétil. 89, 500; from Chem. Abstr. (1949), 43, 8434.

Stamp, Lord (1947). The preservation of bacteria by drying. J. gen. Microbiol. 1, 251.

Sureav, B., Arquie, E., Boyer, F. \& Saviard, M. (1948). Premières données sur la production d'une 'streptomycinase' par certaines souches microbiennes. Ann. Inst. Pasteur, 75, 169. 
TUrfitT, G. E. (1936). Bacteriological and biochemical relationships in the pyocyaneus-fiuorescens group. Biochem. J. 30, 1323.

WisE, W. S. (1951). The measurement of the aeration of culture media. J. gen. Microbiol. 5, 167.

\title{
EXPLANATION OF PLATE
}

\section{Plate 1}

Fig. 1. Assay plate showing zones of exhibition produced by antagonist in nutrient agar deep-seeded with Bacillus pumilus and containing an inhibitory concentration of dihydrostreptomycin.

Fig. 2. Antagonist crystallized to constant activity from ethanol. (a) normal illumination; (b) showing birefringence in polarized light. $\times 300$.

\section{APPENDIX}

\section{LARGE-SCALE PREPARATION OF ANTAGONIST}

Inoculum

\author{
Growth of 300 L. Batch
}

(1) An ampoule containing freeze-dried Pseudomonas aeruginosa, strain L III, was inoculated into $100 \mathrm{ml} .1 \%$ Evans peptone ( $\mathrm{pH} 7 \cdot 0$ ) in a 1 l. conical flask, and incubated on the shaker (84 oscillations/min., length of throw $7 \cdot 5 \mathrm{~cm}$.), at a temperature of $33-35^{\circ}$.

(2) $5 \times 11$. conical flasks, each containing $150 \mathrm{ml}$. ammonium lactate medium, were inoculated with $5 \mathrm{ml}$. of peptone culture and incubated on the shaker for $5 \mathrm{hr}$.

(3) The $5 \mathrm{hr}$. ammonium lactate cultures were bulked and $150 \mathrm{ml}$. volumes used to inoculate each of four stirred flasks each containing 4 l. ammonium lactate medium and $4.8 \mathrm{~g}$. silicone D.C. antifoam (added before sterilization as $1 / 5$ solution in chloroform). The stirred flasks were incubated at $33-\mathbf{3 5}^{\circ}$, stirred at 600 r.p.m. and aerated with $9 \mathrm{l}$. air $/ \mathrm{min}$. for $5 \mathrm{hr}$. Conditions were equivalent to an 'aeration constant' (Wise, 1951) of $1.45 \mathrm{~min}^{-1}$.

(4) The $5 \mathrm{hr}$. stirred cultures were mixed together and used to seed the 100 gal. fermenter (Kelly et al. 1952).

\section{Conditions for growth in 100 gallon fermenter}

Medium $\quad 300 \mathrm{l}$. ammonium lactate medium (ammonium lactate, $\mathbf{0 . 5} \%$; $\mathrm{K}_{2} \mathrm{HPO}_{4}, 0.1 \% ; \mathrm{MgSO}_{4} .7 \mathrm{H}_{2} \mathrm{O}, 0.05 \%$; distilled water to $300 \mathrm{l}$.; $\mathrm{pH}$ value adjusted to $7 \cdot 2$ ).

Antifoam 200 g. silicone D.C. antifoam.

Stirring 200 r.p.m. Conditions to give 'aeration constant' = Aeration 13-14 cu.ft. $/ \mathrm{min}\} .1.45 \mathrm{~min}^{-1}$ (Wise, 1951).

Temperature $\quad 33-35^{\circ}$.

Duration of incubation $\quad 24 \mathrm{hr}$.

Final $\mathrm{pH}$ value of culture $\mathbf{8 \cdot 8}$.

Potency of final culture $\quad 1 \cdot 3 \mathrm{u}$. antagonist $/ \mathrm{ml}$.

Foaming occurred after $9 \mathrm{hr}$. of incubation and was controlled by the addition of a further $50 \mathrm{~g}$. silicone D.C. antifoam. 
Journal of General Microbiology, Vol. 11, No. 3

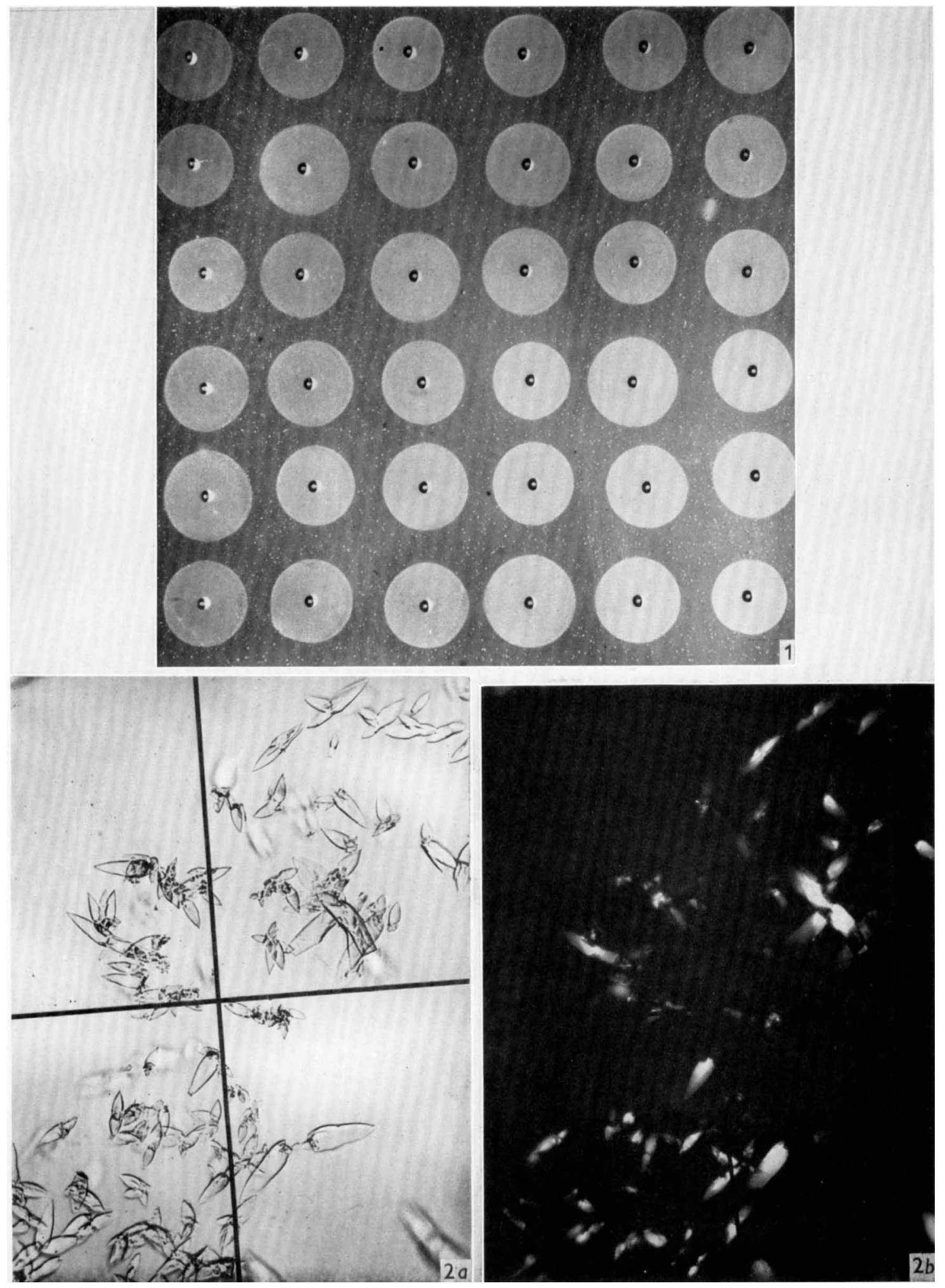

J, W. Lightbown. Streptomycin antagonist from P. abruginosa 

Stage 1

\section{Extraction}

$\begin{array}{ll}\text { Volume of culture } & 300 \mathrm{l} . \\ \text { Potency } & 1 \cdot 4 \mathrm{u} . / \mathrm{ml} . \\ \text { Total units } & 420,000 \\ \text { pH value } & 8 \cdot 9\end{array}$

Culture cooled to $24^{\circ}$ and adjusted to $\mathrm{pH} 5 \cdot 2$ by addition of $500 \mathrm{ml}$. of conc. $\mathrm{HCl}$ (A.R.).

Added $45 \mathrm{l}$. of $n$-butanol and mixed by stirring at 200 r.p.m. for $1 \mathrm{hr}$. Intimate mixing was essential because of the low solvent: culture ratio; shorter time of contact did not give complete extraction.

Allowed to stand overnight.

Separated the two layers:-

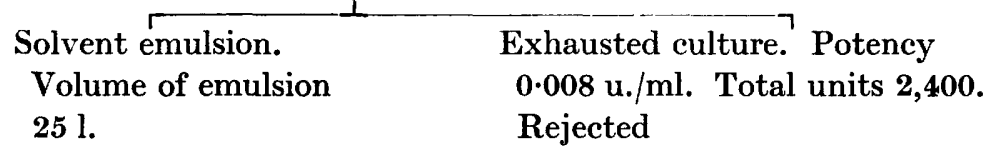

Added 10 l. of light petroleum $\left(80-100^{\circ}\right)$, mixed gently and allowed to stand $2 \mathrm{hr}$. (The addition of light petroleum cracks the emulsion, giving two clear liquid phases containing insoluble suspended matter.) The two layers were separated and the aqueous layer rejected. The solvent mixture layer was filtered through filter-paper pulp.

Volume 25 l. Total units 500,000.

The $25 \mathrm{l}$. was concentrated in an atmosphere of $\mathrm{N}_{2}$ by using a van Heyningen vacuum still (1949); temperature $<60^{\circ}$, to a volume of 1.51 . Total units 450,000. If at this stage the butanol extract was saturated with water and stored at $4^{\circ}$ overnight, silicone separated and could be rejected.

The remaining solvent was removed by distillation in a stream of oxygen-free nitrogen at atmospheric pressure, leaving a dark brown oil.

The oil (volume $c .50 \mathrm{ml}$.) was dissolved in $50 \mathrm{ml}$. warm benzene (A.R.), total units 312,000. (Some loss of activity, during the removal of last traces of solvent, appears unavoidable, but when nitrogen not freed from oxygen is used the losses are usually about $60 \%$.) This benzene solution was then treated as in the tabular description of Stage 2. (See p. 492.) 
$50 \mathrm{ml}$. benzene solution containing

$100,000 \mathrm{u}$. Added $500 \mathrm{ml}$. light petroleum $\left(80-100^{\circ}\right)$. Allowed to stand overnight at $4^{\circ}$. Separated by centrifugation the precipitate formed

Precipitate $\stackrel{\text { Supernatant }}{\text { Sute }}$

Oil, dark purple brown in colour.

Volume $550 \mathrm{ml}$. Total units $\mathbf{5 3 0 0}$

Weight 1-1.5 g. Total units 79,000.

Activity 52-79 u./mg.

Dissolved in $50 \mathrm{ml}$. warm benzene.

Added $100 \mathrm{ml}$. light petroleum

$\left(80-100^{\circ}\right)$. Resulting precipitate im-

mediately centrifuged and separated

Precipitate Supernatant

Oil, dark purple brown in colour.

Weight $720 \mathrm{mg}$. Total units 14,750

Added further $100 \mathrm{ml}$. light petroleum $\left(80-100^{\circ}\right)$. Immediate precipitation. Allowed to stand overnight at $4^{\circ}$. Filtered

Precipitate
Buff colour, crystalline. Washed with
small vol. $1: 4$ benzene light petro-
leum mixture. Weight $658 \mathrm{mg}$. Total
units 60,500 . Activity $92 \mathrm{u} . / \mathrm{mg}$.
Supernatant

Volume $250 \mathrm{ml}$. Total units $\mathbf{5 6 0 0}$

Dissolved in $50 \mathrm{ml}$. warm benzene.

Added $100 \mathrm{ml}$. light petroleum

$\left(80-100^{\circ}\right)$. Precipitate formed: im-

mediately centrifuged and separated

Precipitate 1 Supernatant

Small amount oil. Dark purple brown. Added further $100 \mathrm{ml}$. light petroleum Not weighed or assayed. $\left(80-100^{\circ}\right)$. Immediate precipitation. Allowed to stand overnight at $4^{\circ}$. Filtered

\section{Precipitate Supernatant}

Pale yellow crystalline. Weight $464 \mathrm{mg}$. Volume $250 \mathrm{ml}$. Total units 6600

Total units 57,000. Activity

$123 \mathrm{u} . / \mathrm{mg}$.

\section{Recrystallization}

From benzene: dissolved at $100 \mathrm{mg} . / \mathrm{ml}$. in hot benzene, filtered and allowed to crystallize. Recovery: $80-90 \%$.

From $33 \%$ ethanol in water: dissolved in minimum volume of boiling aqueous ethanol $(30 \%)$, filtered and allowed to crystallize. Recovery: $80 \%$.

(Received 28 June 1954) 